\title{
Insights into the fabrication and structure of plutonium pyrochlores as nuclear waste form
}

\author{
S. FinKELDEI ${ }^{1,2 *}$, M. C. STENNETT ${ }^{3}$, P. M. KOWALSKI ${ }^{2}$, \\ N. HYATT ${ }^{3}$, D. BOSBACH ${ }^{2}$, F. BRANDT ${ }^{2}$
}

${ }^{1}$ University of California, Irvine, CA, 92617, US

${ }^{2}$ Forschungszentrum Juelich, IEK-6, 52425 Juelich, Germany

${ }^{3}$ University of Sheffield, S1 3JD, UK

(*correspondence: sfinkeld@uci.edu)

Rare earth zirconates $\left(\mathrm{A}_{2} \mathrm{~B}_{2} \mathrm{O}_{7}\right)$ with the pyrochlore crystal structure have been suggested as potential nuclear waste forms for actinide immobilization, e.g for separated plutonium from dismantling of nuclear weapon programs. This study presents a wet-chemical coprecipitation route to fabricate $\mathrm{Nd}_{2} \mathrm{Zr}_{2} \mathrm{O}_{7}$ pyrochlores with 5 and $10 \mathrm{~mol} \% \mathrm{Pu}$ content [1]. $\mathrm{Pu}\left(\mathrm{NO}_{3}\right)_{4}$ was dissolved in nitric acid and was mixed with aqoues $\mathrm{Nd}\left(\mathrm{NO}_{3}\right)_{3}$ and $\mathrm{ZrOCl}_{2}$ solutions to coprecipitate the metal hydroxides. The washed precipitate was dried and calcined under reducing atmosphere $\left(\mathrm{Ar}-5 \% \mathrm{H}_{2}\right)$. Pellets were sintered at $1450{ }^{\circ} \mathrm{C}$ under reducing atmosphere. SEM analysis indicated a homogeneous uptake of $\mathrm{Pu}$ within the pellets and XRD measurements confirmed crystallisation in the pyrochlore crystal structure. X-ray absorption spectroscopy revealed the majority of $\mathrm{Pu}$ to be in the tetravalent oxidation state. $\mathrm{Pu}$ LIII-edge EXAFS measurements showed $\mathrm{Pu}$ to occupy the A-site within the pyrochlore crystal structure. The A-site is characterized by eight nearest neighbors with six longer $\mathrm{A}-\mathrm{O}_{48 \mathrm{f}}$ and two shorter A-O 8 b bonds. In order to obtain a reasonable fit of the EXAFS data the degeneracies of the two Pu-O1 paths were inverted to give six short $\mathrm{Pu}-\mathrm{O}$ and two long $\mathrm{Pu}-\mathrm{O}$ paths, indicating a significant distortion of the A-site environment in a pyrochlore structure. On average the nearest neighbor $\mathrm{Pu}-\mathrm{O}$ bond lengths were determined to be $2.35 \AA \pm 0.03$ for $\mathrm{Nd}_{1.9} \mathrm{Pu}_{0.1} \mathrm{Zr}_{2} \mathrm{O}_{7}$ and $2.33 \AA \pm 0.03$ for $\mathrm{Nd}_{1.8} \mathrm{Pu}_{0.2} \mathrm{Zr}_{2} \mathrm{O}_{7}$. These findings were supported by the bond valence sum approach. DFT $a b$ initio calculations supported the experimental findings. Immobilization of $\mathrm{Pu}(\mathrm{IV})$ on the usually trivalent $\mathrm{A}$ site with charge compensation via oxygen atoms at former vacant sites resulted in the lowest solution energies of $\mathrm{Pu}$ in pyrochlore. Eventhough the incorporation of $\mathrm{Pu}(\mathrm{IV})$ at the Asite results in significant distortion of the A-site local geometry, XRD confirmed the long range pyrochlore structure and the structural uptake of $\mathrm{Pu}(\mathrm{IV})$ into the pyrochlore structure.

[1] S. Finkeldei, M.C. Stennett, et al. (2020) J. Mater. Chem. A 8, 2387-2403. 